\title{
Tracking in High School Mathematics: Individual, Social, and School-Based Determinants in an Education Reform Context
}

\author{
Valérie Lessard ${ }^{1}$, Simon Larose ${ }^{1}$, Stéphane Duchesne ${ }^{1} \&$ Bei Feng ${ }^{1}$ \\ ${ }^{1}$ Laval University, Québec, Canada \\ Correspondence: Simon Larose, Faculty of Education, Laval University, Québec, Québec, G1V 0A6, Canada. \\ E-mail: simon.larose@fse.ulaval.ca
}

Received: August 20, 2014

Accepted: October 2, 2014

Online Published: October 15, 2014

doi:10.5539/jedp.v4n2p102

URL: http://dx.doi.org/10.5539/jedp.v4n2p102

This research was supported by a grant to the second and third authors from the Québec Ministry of Education.

\begin{abstract}
The aim of this study was to explore the predictive links between individual, social, and school-based factors and mathematics tracking in high school in the context of the Quebec mathematics education reform. Students and their parents first completed questionnaires in 2006 when the students were in second year high school (Time 1), and again in 2008 after course placement (Time 2). Logistic regression results indicated that a large proportion of variance was explained by the model (pseudoR2 at 0.31-0.37). Previous performance in math, participation in a specialized high school program, and private or public school status were the strongest determinants of math placement. Above and beyond these factors, parents' education level and students' perceived support from parents and friends in choosing a mathematics course also showed positive and significant associations with math placement. Implications of these findings for mathematics tracking in high school and student development are discussed.
\end{abstract}

Keywords: academic tracking, mathematics, math placement, high school, social factors, school-based factors, individual factors

\section{Introduction}

Many countries, including Canada, the United States, India, and the United Kingdom, are coping with a shortage of qualified workers, particularly in the fields of mathematics, sciences, and technologies (MST) (Direction de la recherche en politiques et coordination, 2004; Russo, 2009; Smith \& Gorard, 2011). For example, in the province of Quebec, Canada, job opportunities in the natural and applied sciences are expected to rise dramatically (67,000 new jobs per year) from 2009 to 2019, even as the number of available workers is declining (Direction de l'analyse et de l'information sur le marché du travail d'Emploi-Québec, 2010). At the same time, certain countries, including the United States, are facing a lack of qualified MST teachers, making it even more difficult to prepare the next generation of scientists (Ingersoll \& Perda, 2010). This workforce deficit will wield a heavy social impact on the countries concerned, with effects on market competitiveness as well as the quality of social and educational service delivery (see Smith \& Gorard, 2011). It is therefore important to understand the origins of the workforce shortage in MST.

One factor proposed by many researchers to explain this workforce deficit is the underrepresentation of youths in advanced high school math courses (Ma \& Johnson, 2008). In fact, although some consider access to advanced math courses as a privileged gateway to a scientific career (e.g., Pajares \& Graham, 1999), this access depends largely on the tracking system used to place youths into high school math courses, along with associated individual, school-based, and social factors.

In the present article, individual, social, and school-based determinants of math tracking in high school were examined in the context of an education reform. Among other things, this reform was aimed to motivate students to enter careers in MST by structuring the math content to better fit the students' different needs, interests, and abilities and by increasing the support offered to students when choosing math courses (Québec ministère de l'Éducation, du Loisir et du Sport-Quebec's ministry of education - MELS, 2006). We begin with a review of 
the main studies on high school math tracking, followed by a description of the specific context of our study and Quebec's recent math education reform.

\subsection{Conceptualization and Determinants of Course Placement}

Academic tracking refers to the grouping of students into classes or programs according to their ability and academic needs. There are two main forms of tracking in high school. The first involves placing students in a certain program, stream, or path for an entire school curriculum extending over one or several years (e.g., a sport-study, vocational, or academic program), and the second, which is more commonly used in Quebec for math, involves dividing up students in a given subject (e.g., French or math) and then classifying them according to ability (Oakes, 1987). This type of grouping can be applied to a single course or a subject course sequence. In one form or another, tracking has become common practice in many countries, including the United States, Japan, Germany, Great Britain, and Israel (Oakes, Gamoran, \& Page, 1992).

Student involvement in the tracking process varies across schools. In some schools, the administration decides on the placement procedure, and in others, the students themselves and their parents provide most of the input (Oakes \& Guiton, 1995). Still other schools use a mixed approach that accounts for the students' preferences as well as certain selection criteria. Because students are sometimes involved in the math tracking process, the studies reviewed in the next sections address the determinants of both placement and the choice to take advanced math courses.

\subsubsection{Individual Determinants}

The influence of diverse individual student characteristics on academic tracking has been largely studied. Of these characteristics, previous performance stands out as the most influential on math placement (Alexander \& Cook, 1982; Hallinan, 1992; Kelly, 2004). Higher previous performance was found to increase the odds of being placed in an advanced math course (Oakes \& Guiton, 1995; Resh, 1998). Moreover, the literature on academic choice shows that previous performance was one of the most important factors in the choice to take advanced math courses (Ma, 2001).

Other individual factors that exert a more moderate influence have been taken into account to explain math placement. Researchers have found a positive relationship between student motivation (generally defined in terms of interest, usefulness, and perceived competence) and their placement in an advanced math course (Ireson \& Hallam, 2009; Lessard, Chouinard, \& Bergeron, 2009; Ma, 2001; Pajares \& Miller, 1995). In the literature on academic choice, one study indicated that motivation toward math had a positive influence on students' decisions, and this influence grew during adolescence (from grade 7 to 12) (Ma, 2001), such that by the end of high school, attitude toward math was more strongly determinant than marks for the choice to take advanced math courses. Ireson and Hallam (2009) obtained similar results, indicating that self-perceptions with respect to math (defined as students' perceived competence, interest, and pleasure in math) had more influence than previous performance on the choice to take advanced math courses in late adolescence.

Finally, in many studies, gender was found related to course placement (Hallinan, 1992; Ma, 2001; Oakes \& Guiton, 1995; Resh, 1998). With performance held equal, girls were less likely than boys to be placed in advanced courses (Hallinan, 1992). A study conducted in Quebec in a sample of 3,711 students showed a similar trend (Lessard, 2007). Above and beyond previous motivation toward math, girls were 6.6 times less likely than boys to be placed in an advanced course sequence in high school (Lessard, 2007). Other studies have shown that the effect of gender on the advanced math choice was moderated by student motivation (Crombie et al., 2005; Watt, 2008). Boys with high motivation (i.e., perceived competence and usefulness) were more likely to choose an advanced math course compared to girls with high motivation, whereas no such gender differences were found for students with low motivation.

\subsubsection{Social Determinants}

Some studies have indicated that students from economically advantaged families have greater access to advanced math courses (Kelly, 2004; Ma, 2001). Moreover, the influence of family social status acted independently of students' academic achievement in predicting math placement (Kelly, 2004). Furthermore, having well educated parents was associated with a greater probability of placement in an advanced math course, independently of previous performance (Schiller, Schmidt, Muller \& Houang, 2010).

To our knowledge, few studies have addressed the potential influence of support from parents, peers, and educators on course placement. One study indicated that, among a large number of social variables, including peers' academic aspirations, encouragement by father and mother, and having conversations with teachers and 
guidance counselors, only peers' academic aspirations was related to math placement (Alexander \& Cook,1982). On the other hand, the literature on social support determinants of academic choices is more abundant. Some studies have identified parental support as a positive factor in the choice to take advanced math (see Ma, 2001), while others have found support from counselors as a key influence (Resh \& Erhard, 2002; Spade, et al., 1997). Ma's (2001) results showed instead that students got involved in math based more on their own motivation and aspirations than on support received from significant others at school. For motivated students, only parental support had a significant but weak influence. Thus, more motivated students who were encouraged by their parents were more likely to take advanced math (see Ma, 2001). Still other researchers concurred that peer influence was a non-negligible factor in students' academic choices (e.g., Engberg \& Wolniak, 2010).

\subsubsection{School-Based Determinants}

Students with similar dispositions may end up placed in different academic tracks, depending on certain characteristics of the school tracking system. The number of subjects divided up into sequences, the number of sequences offered, and whether or not simultaneous tracking was used are factors that were found related to course placement (Jones, Vanfossen, \& Ensminger, 1995; Hallinan, 1992). Generally, less flexibility and greater number of sequences were related to less access to advanced courses. Some researchers also proposed that many characteristics of schools, such as private or public status, rural or urban setting, size, and economic environment might also influence the tracking process (Oakes \& Guiton, 1995; Spade, Columba, \& Vanfossen, 1997). For instance, students from advantaged neighborhoods and from private schools had greater access to courses such as advanced math and sciences than students attending schools in disadvantaged neighborhoods and public schools (Oakes \& Guiton, 1995; Epple, Newton, \& Romano, 2002). Researchers largely agree that the school's organization and status affect its tracking system, which in turn affects students' academic ambitions and choices (Oakes, 1987).

\subsection{The Present Study}

In sum, many researchers suggest that individual, social, and school-based factors must be considered to better understand the determinants of math placement (Ma, 2001; Oakes, 1987; Oakes \& Guiton, 1995). Unfortunately, few studies to date have accounted for all these factors in a single predictive model to assess their relative and additive influence. Moreover, because most studies were conducted from 1980 to 1990 (e.g., Nagy et al., 2008; Kelly, 2004), recent data are comparatively rare. Given that several education reforms have been undertaken over the past two decades, it appeared relevant to conduct a more in-depth examination of the relative influence of a wider range of factors on math tracking.

Consequently, the aim of the present study was to examine the relative and additive contribution of individual, social, and school-based factors in predicting math placement. These factors include: (a) motivation and gender (individual), (b) parents' education level, family income, and perceived support from parents, friends, teachers, and counselors in making a choice (social), and (c) school's socioeconomic status, enrollment in a specialized program, school size, private or public school status, and rural or urban setting (school-based). The respective contribution of these factors was examined in the context of Quebec's recent education reform. Since 2008, fourth year high school students in Quebec have been placed into one of three new course sequences that were designed to meet the students' different needs, interests, and training requirements (MELS, 2007): the Culture, Social and Technical (CST) sequence, the Technical and Scientific (TS) sequence, or the Science (S) sequence. These sequences include two math courses (taken over two years), and they differ in terms of the level of complexity. The TS and S sequences have more advanced content and prepare students to enter higher education programs in all fields, whereas the CST sequences limit access to MST careers. The sequences are not imposed by the schools. Instead, counselors, teachers, and parents are encouraged to help students explore their interests, needs, and aspirations so that they can make an appropriate choice, which the school must take into account in the placement process.

Because the reform offers three sequences, of which two are equivalent in terms of future opportunities, we developed two main hypotheses for this study. In a first model, we wanted to determine what distinguishes students who were placed in an advanced sequence (TS or S) from those placed in a basic sequence (CST). From the literature review, we would expect the choice to take an advanced rather than a basic sequence to be determined largely by the student's previous performance and motivation. Other factors should show a more moderate but still significant association.

In a second model, we wanted to determine distinctions between students placed in the two advanced sequences (TS vs. S). Given that the main tracking principle is student's choice, and that the two sequences are at an 
equivalent level of complexity, we hypothesized that course placement would be determined more by student motivation and the perceived support they received in making the choice than by their previous performance. School size, status, and setting (rural vs. urban) should also be determinants. Given the advanced level of the two sequences, we felt that the other factors would not be significant in this model.

Finally, we wanted to explore whether student gender and the school's socioeconomic status would moderate the effects of the other predictive variables in the math tracking model. Because the main tracking criterion for math under the Quebec reform is student's choice, the above-presented results from the literature suggest that individual variables (previous performance, perceived competence, perceived usefulness, and interest in math and science) as well as social variables (perceived support in making the choice) should be differentially associated with placement according to gender. Furthermore, because tracking frequently favors students who are advantaged to begin with, we wanted to determine whether attending a less advantaged school would affect the other variables and lower the odds of being placed in an advanced sequence.

\section{Method}

\subsection{Participants and Procedure}

A random sample of 2,000 phone numbers of parents who had a child beginning their second year of high school in the province of Quebec in autumn 2007 was obtained from the MELS. Research assistants called all 2,000 parents and invited them and their child to complete questionnaires at two occasions: in spring 2008 when the children were completing their second year of high school (Time 1), and again in spring 2010 after course placement (Time 2). Of the 2,000 parents and children called, 1,315 agreed to participate and completed the first questionnaire (initial sample). At time 2, 883 parents and their children sent back the second questionnaire, for a $33 \%$ overall sample attrition. In view of the objectives of the present study, only students who responded to the question on math course placement at Time 2 were retained. The final sample therefore included 732 students (41.3\% boys, $58.7 \%$ girls) from 317 high schools representing all regions of Quebec. The students attended schools in French (84.7\%) and English (15.3\%) located in various socioeconomic settings. In addition, 23.6\% of the students attended a private school. Of the parents who responded, $66 \%$ were mothers and $34 \%$ were fathers. Parents' average annual income ranged from $\$ 30,000$ to $\$ 40,000$. In terms of education, $46 \%$ had a university degree and $30 \%$ had graduated from college.

Results of chi square tests and $t$ tests showed that the final sample differed slightly but significantly from the initial sample on several individual and demographic variables. However effect sizes were weak, ranging from 0.01 to 0.17 . The participants retained for the present study were slightly more academically advantaged than the initial sample. Notably, fewer students had repeated a primary school grade, $\chi^{2}(2, \mathrm{n}=1371)=37.521, \mathrm{p}<0.001$, more students came from well-off families, $\mathrm{t}(818)=5.082, \mathrm{p}<0.001$, that were well educated, $\chi^{2}(2, \mathrm{n}=1392)=$ $29.743, \mathrm{p}<0.001$, and more students were attending a private school, $\chi 2(1, \mathrm{n}=1271)=12.526, \mathrm{p}<0.001$, or a socioeconomically advantaged public school, $\mathrm{t}(1031)=-3.375, \mathrm{p}<0.01$. Girls, $\chi 2(1, \mathrm{n}=1395)=7.095, \mathrm{p}<0.01$, were slightly more predominant than in the initial sample, and students spent more time on homework per week on average, $\mathrm{t}(1215)=3.105, \mathrm{p}<0.01$.

\subsection{Measurement}

\subsubsection{Math Placement}

Students indicated the fourth year mathematics sequence in which they were placed at Time 2: the Culture, Social and Technical (CST) sequence, the Technical and Scientific (TS) sequence, or the Science (S) sequence.

\subsubsection{Individual Variables}

In order to assess previous math performance, students responded to the following statement at Time 1: "Over this school year, and according to your report card, how would you rate your average performance in mathematics?" Marks were expressed as percentages. Gender was coded 0 for boys and 1 for girls.

Perceptions of competence in math were assessed at Time 1 using a four-item subscale adapted from the Échelle des perceptions de compétence dans les domaines de vie (Perceived Competence in Life Domains Scale EPCDV) developed by Losier, Vallerand, and Blais (1993). The items measure students' confidence in their ability to learn and succeed in math (e.g., "Overall, I believe that I was a good student in this course") $(\alpha=0.80)$. Participants responded on a seven-point Likert scale ranging from 1 (strongly disagree) to 7 (strongly agree).

Perceived usefulness of math courses at Time 1 was measured using a subscale of a shortened version of Fennema and Sherman's (1976) Mathematics Attitudes Scales, translated into French and validated by Vezeau, 
Chouinard, Bouffard, and Couture (1998). The usefulness subscale includes six items that measure students' perceptions of math courses as being useful and therefore relevant to their current and future goals (e.g., "I'll need mathematics for my future work") ( $\alpha=0.78)$.

General interest in mathematics and sciences was measured at Time 1 using five items developed and validated by our research group. The preliminary analysis results showed that the scale presents good psychometric properties $(\alpha=0.67$; inter-item correlations at $0.18-0.49)$. The items measured students' interest in math and science (e.g., "I like to talk about scientific things with other people") $(\alpha=0.67)$. Participants responded on a five-item Likert scale ranging from 1 (strongly disagree) to 5 (strongly agree).

\subsubsection{Social Variables}

At Time 1, parents completed a questionnaire addressing their gross annual family income and education level (determined as the highest level completed by one of the parents, either the respondent or respondent's partner). Other researchers have included this variable to examine the effect of family on tracking (Falter, Luzzi, \& Sbergami, 2010). Parent's education level was coded 0 for completion of elementary school or high school, 1 for a college diploma or certificate, and 2 for a university degree. Gross annual family income was coded 1 for less than $\$ 20,000,2$ for $\$ 20,000$ to $\$ 30,000,3$ for $\$ 30,000$ to $\$ 40,000$, and up to 10 for $\$ 100,000$ or more.

At Time 2, students indicated their perceptions of support received from various people in choosing a math sequence, using the following statement: "These persons (parents, teacher, friends, counselor) helped me choose my fourth year math course.” They responded for each person on a five-item scale ranging from 1 (not at all) to 5 (very much).

\subsubsection{School-Based Variables}

An index produced by the MELS was used to assess the school's socioeconomic status (SSSI) (MELS, 2008), calculated for the 2006-2007 school year, which corresponds to the first year of high school for the study participant. This index is determined based on the percentage of families with children at school whose mothers do not have a diploma, certificate, or degree and the percentage of households whose parents were not employed during a reference week. The SSSI is rated on a scale from 1 to 10 , where 1 represents a highly advantaged environment and 10 represents a highly disadvantaged environment.

Students' parents confirmed whether their child was enrolled in a specialized program in second year high school: an enriched program or a sport-study program. Data on school size, private or public status, and rural or urban setting for the 2006-2007 school year were obtained from the MELS.

\subsection{Analytic Design}

The proposed hypotheses were tested with two models. Model 1 was designed to determine placement in an advanced sequence (TS or S) over the basic sequence (CST). Model 2 was designed to test the determinant factors for placement in one of the two advanced sequences over the other (S vs. TS). Interactions between individual and social variables and gender and SSSI were then entered to determine whether the predictive model fits equally well for boys and girls and for students who were attending schools with differing socioeconomic status.

\subsubsection{Preliminary Analysis}

We began with descriptive analyses (means, standard deviations, and frequencies), using SPSS version 19, to examine the distribution of responses on the different variables and to assess the distribution of students in the different sequences in terms of gender, parents' education, enrollment in a specialized program, private or public school status, and rural or urban setting. Chi square tests were run to detect significant differences between groups. A bivariate correlation analysis was then performed to select a set of initial variables for a more parsimonious model with a good data fit.

\subsubsection{Principle Analysis}

Logistic regression analyses were performed, using Mplus, version 5.2, to test the proposed hypotheses. This procedure was deemed appropriate to classify the participants according to a series of two-level categorical predictors. Thus, the variable placement was dichotomized differently for the two models to meet the study objectives. Continuous variables were standardized to facilitate the interpretation of the interaction effect results. Full information maximum likelihood was used to minimize bias due to missing data (i.e., partial responses on some variables). This procedure is applied when missing data are the result of randomness: the probability for 
missing variable data is either completely random or dependent on other variables, but not dependent on the variable itself. The percentage of missing variable data ranged from $2.0 \%$ to $10.9 \%$.

\section{Results}

\subsection{Preliminary Analysis Results}

The distribution of students in the three math sequences is presented in Table 1. Twenty-six percent of the students were in the CST sequence, $27 \%$ in the TS sequence, and $47 \%$ in the SN sequence. Belonging to a math sequence was not related to gender, $\chi^{2}(2, \mathrm{n}=717)=1.09, \mathrm{p}=0.58$, or to the school setting, $\chi^{2}(2, \mathrm{n}=732)=$ $0.60, \mathrm{p}=0.74$. On the other hand, belonging to a math sequence was significantly related to the parents' education level, $\chi 2(4, \mathrm{n}=715)=28.78, \mathrm{p}<0.001$, student's previous participation in a specialized program, $\chi^{2}$ $(2, \mathrm{n}=690)=43.86, \mathrm{p}<0.001$, and school status, $\chi^{2}(2, \mathrm{n}=732)=14,35, \mathrm{p}<0,001$.

Table 1. Cross-tabulation of the number of students in a given sequence by gender, parents' education level, enrollment in a specialized program, school's private or public status, and school's rural or urban setting

\begin{tabular}{lllll}
\hline & \multicolumn{4}{l}{ Mathematics sequences } \\
\cline { 2 - 3 } & CST & TS & SN & Total \\
\hline Gender & 84 & 77 & 135 & 296 \\
Boy & 105 & 117 & 199 & 421 \\
Girl & & & & \\
Parents' education level & 51 & 31 & 46 & 128 \\
Elementary, High school & 68 & 57 & 88 & 213 \\
College & 69 & 106 & 199 & 374 \\
University & & & & \\
Specialized program & 130 & 113 & 139 & 382 \\
No & 48 & 76 & 184 & 308 \\
Yes & & & & \\
School status & 163 & 135 & 261 & 559 \\
Public & 30 & 63 & 80 & 173 \\
Private & & & & \\
School setting & 21 & 24 & 34 & 79 \\
Rural & 172 & 174 & 307 & 653 \\
Urban & 193 & 198 & 341 & 732 \\
Total & & & & \\
\hline
\end{tabular}

Note. The total $\mathrm{N}$ varies for the variables gender, specialized program, and parents' education level (data treated before imputation).

As calculated from the Table 1 data, the proportion of students who have at least one parent who did not complete college (i.e., elementary or high school level only) was higher in the CST sequence (27\%) than in the TS (16\%) and SN (14\%) sequences. Similarly, the proportion of students who had at least one parent with a university diploma was lower in the CST sequence (37\%) than in the TS (55\%) and SN $(60 \%)$ sequences.

A substantial proportion of students (45\%) had been enrolled in a specialized program in second year high school (sport-study or enriched program), but this proportion differed across sequences: it was higher in the TS (40\%) and SN (57\%) sequences than in the CST sequence (27\%). Finally, higher proportions of students had attended a private school in the TS (32\%) and SN (24\%) sequences than in the CST sequence (16\%). 
Table 2 presents the correlations among all the predictor variables as well as the variable means and standard deviations. In order to test the most parsimonious model, the variables gender, SSSI, perceptions of support from counselor, and rural or urban setting were excluded from further analysis because their association with the dependent variable was not significant in this initial step. However, in order to determine their potential moderating effect, the interactions Gender by other predictors and SSSI by other predictors were added to the final analysis model.

\subsection{Logistic Regression Results}

\subsubsection{Model 1}

The first model was designed to determine the variables associated with placement in an advanced course sequence (TS or S) over a basic sequence (CST). The dependent variable was therefore recoded as 0 for CST and 1 for TS or $\mathrm{S}(\mathrm{n}=732)$. We first tested the main model and subsequently tested the interaction terms with gender and SSSI. Because the interaction terms were not significant, they were withdrawn in order to obtain a more parsimonious model.

Table 3 presents the retained model. The adjusted model differed significantly from the null model $\lambda^{2}(13)=$ 206.56, $\mathrm{p}<0.001$, showing good data fit (Hosmer-Lemeshow statistic $\chi 2(8)=6.125, \mathrm{p}=0.633$ ). The model explained a high percentage of variance (McKelvey \& Zavoina's pseudo R2 $=0.37$ ). Table 3 presents the factors that were significantly related to TS or S over CST placement. Previous math performance, enrollment in a specialized program, private school status, parents' education level, and perceived support from parents and friends were all predictive of this math placement.

More specifically, the higher the student's previous math performance, the greater the odds that he or she would be placed in an advanced math sequence. For each unit rise in performance in second year high school, the odds of being placed in an advanced over a basic sequence in fourth year were 3.00 times higher. In addition, enrollment in a specialized program in second year increased the odds of placement in an advanced course in fourth year. Thus, students who took a specialized program in second year had a 2.71 greater chance of being placed in an advanced math sequence in fourth year. The results also show that attending a private school increased by 2.24 the odds of being placed in an advanced sequence in fourth year. The chances of advanced placement were also higher for students having at least one parent with a university education: the odds were 1.75 times greater than when the parents had elementary or high school education, and 1.72 times greater than when the parents had college education. Finally, the more students perceived that they had been supported by their parents and friends in choosing a sequence, the greater the likelihood that they would be placed in an advanced sequence.

Table 2. Bivariate correlations (before imputation)

\begin{tabular}{|c|c|c|c|c|c|c|c|c|c|c|c|c|c|c|c|c|c|}
\hline & 1 & 2 & 3 & 4 & 5 & 6 & 7 & 8 & 9 & 10 & 11 & 12 & 13 & 14 & 15 & 16 & $17 \quad 18$ \\
\hline 1. Gender & 1 & & & & & & & & & & & & & & & & \\
\hline 2. Math performance & .043 & 1 & & & & & & & & & & & & & & & \\
\hline 3. Perceived competence & .012 & $.643^{* *}$ & 1 & & & & & & & & & & & & & & \\
\hline 4. Perceived usefulness & .058 & $.202 * *$ & $.328 * *$ & 1 & & & & & & & & & & & & & \\
\hline 5. Interest in sc. \& math & -.075 & $.161^{* *}$ & $.215^{* *}$ & $.216^{* *}$ & 1 & & & & & & & & & & & & \\
\hline 6. Parents' education 1 & .042 & $-.152 * *$ & *-.109* & -.046 & .010 & 1 & & & & & & & & & & & \\
\hline 7. Parents' education 2 & .061 & $-.093^{*}$ & -.064 & -.009 & -.008 & $\mathrm{a}$ & 1 & & & & & & & & & & \\
\hline 8. Family income & -.023 & $.130^{* *}$ & .058 & .013 & -.015 & $-.587^{* *}$ & ${ }^{*}-.362^{* *}$ & & & & & & & & & & \\
\hline 9. Specialized program & .009 & $.152^{* *}$ & .004 & .035 & .036 & $-.227^{* *}$ & $*-.110^{* *}$ & *.158** & 1 & & & & & & & & \\
\hline 10. SSSI & -.049 & -.068 & -.080 & -.014 & .032 & $.268^{* *}$ & $.103^{*}$ & $-.245^{* *}$ & * $-.219 * *$ & & & & & & & & \\
\hline 11. Support from parents & .071 & .031 & .065 & $.079^{*}$ & .015 & $-.182^{* *}$ & $*-.049$ & $.121^{* *}$ & .003 & -.046 & 1 & & & & & & \\
\hline 12. Support from friends & $.118^{* *}$ & -.012 & .022 & .025 & .014 & .002 & .020 & .014 & .053 & .051 & $.466 * *$ & 1 & & & & & \\
\hline 13. Support from teacher & .073 & .057 & $.108^{* *}$ & .070 & .053 & -.039 & -.047 & .054 & -.029 & -.023 & $.344^{* *}$ & $.348 * *$ & 1 & & & & \\
\hline
\end{tabular}




\begin{tabular}{|c|c|c|c|c|c|c|c|c|c|c|c|c|c|c|c|c|c|}
\hline 14. Support from couns. & .042 & -.068 & -.035 & .028 & .059 & .044 & .072 & -.072 & -.059 & $.099 *$ & $.181^{* *}$ & $.150^{* *}$ & $.246^{* *}$ & 1 &.- & & \\
\hline 15. School size & .005 & .006 & .021 & -.018 & -.006 & $-.104 *$ & -.060 & $.100 * *$ & $.181^{* *}$ & $-.302 * *$ & -.068 & .034 & -.042 & $-.133 * *$ & 1 & & \\
\hline 16. Private/Public school & -.068 & -.016 & .026 & .047 & -.018 & $-.219 * *$ & $*-.222 * *$ & $* .259 * *$ & $-.144 * *$ & & .029 & -.024 & .024 & .000 & $-.092 *$ & 1 & \\
\hline 17. Rural/Urban school & -.038 & .061 & .069 & .014 & -.001 & $-.146^{* *}$ & ${ }^{k}-.105^{*}$ & $.098 *$ & $.139^{* *}$ & $-.320 * *$ & $*-.053$ & $-.108^{* *}$ & $k^{k}-.041$ & $-.077^{*}$ & $.290 * *$ & .048 & 1 \\
\hline 18. Sequence model 1 & .038 & $.455^{* *}$ & $.297 * *$ & $.140 * *$ & $.132 * *$ & $-.219^{* *}$ & $-.153^{* *}$ & $* .145 * *$ & $.210^{* *}$ & -.023 & $.159^{* *}$ & $.107 * *$ & $.074 *$ & .003 & -.022 & $.114 * *$ & .0021 \\
\hline 19. Sequence model 2 & -.007 & $.288^{* *}$ & $.198 * *$ & $.130^{* *}$ & $.114^{*}$ & -.046 & -.044 & .012 & $.162^{* *}$ & -.017 & -.011 & .020 & .040 & -.085 & $.171^{* *}$ & $-.091^{*}$ & $.033 \mathrm{a}$ \\
\hline Means & & 80.69 & 5.49 & 4.52 & 3.10 & & & 6.89 & & 5.04 & 2.92 & 2.18 & 2.73 & 1.73 & 1034 & & \\
\hline Standard Deviations & & 10.90 & 1.17 & 0.60 & 0.85 & & & 3.01 & & 2.85 & 1.46 & 1.27 & 1.45 & 1.20 & 553 & & \\
\hline
\end{tabular}

Table 3. Logistic regression results for placement in the TS and S options over the CST option

\begin{tabular}{llllll}
\hline & \multicolumn{7}{l}{ Model 1: TS and S over CST } & \\
\cline { 2 - 4 } & B & E.S. & $\begin{array}{l}\text { Odds } \\
\text { Ratio }\end{array}$ & CI (95\%) & \\
\cline { 5 - 6 } & & & Inf. & Sup. \\
\hline Null model & 1.321 & 0.419 & & & \\
Math performance & 1.099 & 0.145 & $3.002^{* * *}$ & 0.726 & 1.472 \\
Perceived competence & 0.037 & 0.133 & 1.038 & -0.306 & 0.381 \\
Perceived usefulness & 0.073 & 0.104 & 1.075 & -0.196 & 0.341 \\
Interest in math and science & 0.189 & 0.108 & 1.208 & -0.088 & 0.467 \\
Parents' education 1 & -0.561 & 0.309 & $0.571 \sim$ & -1.357 & 0.234 \\
Parents' education 2 & -0.541 & 0.256 & $0.582^{*}$ & -1.201 & 0.120 \\
Family income & -0.002 & 0.044 & 0.998 & -0.115 & 0.111 \\
Support from parents & 0.310 & 0.124 & $1.364^{*}$ & -0.010 & 0.630 \\
Support from friends & 0.242 & 0.123 & $1.274^{*}$ & -0.074 & 0.559 \\
Support from teacher & -0.029 & 0.109 & 0.971 & -0.310 & 0.252 \\
Specialized program & 0.996 & 0.240 & $2.707^{* * *}$ & 0.379 & 1.613 \\
School size & 0.000 & 0.000 & 1.000 & -0.001 & 0.000 \\
Private or public school & 0.806 & 0.272 & $2.239^{* *}$ & 0.106 & 1.506 \\
\hline
\end{tabular}

$* \mathrm{p}<0.05 . * * \mathrm{p}<0.01 .{ }^{* * *} \mathrm{p}<0.001 . \sim \mathrm{p}=0.07$ Note. Comparison category for private or public school $=$ private; Parents' education 1 = elementary, high school, or other; Parents' education 2 = college; Comparison category $=$ university.

\subsubsection{Model 2}

The second model was designed to determine the variables associated with placement in one or the other of the advanced math sequences (TS or S). The dependent variable was therefore coded as 0 for TS and 1 for $\mathrm{S}(\mathrm{n}=539)$. The probability of placement in the S sequence was then estimated. Logistic regression analyses were performed as for Model 1. Interaction effects with gender and SSSI were tested. The model with gender interaction effects is presented because it showed a significant contribution. This model was then compared to the initial model without interaction (Table 4).

The complete model including gender interaction effects differed significantly from the null model, $\lambda^{2}(21)=$ 84.78, $\mathrm{p}<0.001$, and provided a good data fit (Hosmer-Lemeshow statistic, $\chi 2(8)=2.994, \mathrm{p}=0.935)$. The proportion of variance explained by the complete model (pseudoR $2=0.31$ ) was comparable to Model 1 , albeit slightly lower. However, it was higher than for the basic model, which did not include any interactions (pseudoR2 $=0.15$ ). In the basic model, only three variables were significantly related to placement in an $\mathrm{S}$ over a TS sequence. Previous math performance, enrollment in a specialized program, and school size were significant 
at a fixed confidence interval $(p<0.05)$. When interaction effects were introduced, a significant effect of gender combined with perceptions of competence emerged.

Table 4. Logistic regression results for placement in the S over the TS Option

\begin{tabular}{|c|c|c|c|c|c|c|c|c|c|c|}
\hline & \multicolumn{5}{|c|}{ Model 2: S over TS } & \multicolumn{5}{|c|}{ Model 2: with gender interaction } \\
\hline & \multirow{2}{*}{$\mathrm{B}$} & \multirow{2}{*}{ E.S. } & \multirow{2}{*}{$\begin{array}{l}\text { Odds } \\
\text { Ratio }\end{array}$} & \multicolumn{2}{|c|}{ CI $(95 \%)$} & \multirow{2}{*}{$\mathrm{B}$} & \multirow{2}{*}{ E.S. } & \multirow{2}{*}{$\begin{array}{l}\text { Odds } \\
\text { Ratio }\end{array}$} & \multicolumn{2}{|c|}{ CI $(95 \%)$} \\
\hline & & & & Inf. & up. & & & & Inf. & up. \\
\hline Null model & -0.087 & .417 & & & & -0.157 & .448 & & & \\
\hline Math performance & .621 & .149 & $1.862 * * *$ & .237 & .006 & 0.464 & .227 & $1.591 *$ & -0.120 & .048 \\
\hline Perceived competence & 0.118 & .136 & 1.125 & 0.233 & .469 & 0.576 & .224 & $1.780^{*}$ & 0.000 & .153 \\
\hline Perceived usefulness & 0.131 & .115 & 1.140 & 0.166 & .428 & -0.100 & .165 & 0.904 & -0.527 & .326 \\
\hline Interest math/science & 0.162 & .101 & 1.176 & 0.098 & .423 & .330 & .169 & 1.391 & 0.105 & .766 \\
\hline Parents' education 1 & -0.155 & .344 & 0.857 & 1.040 & .730 & -0.095 & .347 & 0.910 & -0.988 & .799 \\
\hline Parents' education 2 & -0.200 & .250 & 0.819 & 0.844 & .445 & -0.185 & .257 & 0.831 & -0.847 & .477 \\
\hline Family income & -0.043 & .044 & 0.958 & 0.158 & .071 & -0.038 & .046 & 0.963 & -0.157 & .082 \\
\hline Support from parents & -0.017 & .116 & 0.983 & 0.317 & .282 & -0.176 & .192 & 0.838 & -0.671 & .318 \\
\hline Support from friends & 0.006 & .116 & 1.006 & 0.292 & .304 & 0.307 & .204 & 1.360 & -0.219 & .833 \\
\hline Support from teacher & 0.096 & .105 & 1.101 & 0.173 & .366 & -0.069 & .163 & 0.934 & -0.490 & .352 \\
\hline Specialized program & 0.504 & .216 & $1.655^{*}$ & 0.053 & .060 & 0.457 & .221 & $1.579 *$ & -0.112 & .026 \\
\hline School size & 0.001 & .000 & $1.001 * * *$ & .000 & .001 & 0.001 & .000 & $1.001 * * *$ & 0.000 & .001 \\
\hline Private or public sch. & -0.249 & .228 & 0.780 & 0.836 & .339 & -0.238 & .237 & 0.788 & -0.848 & .371 \\
\hline Gender & & & & & & -0.045 & .215 & 0.956 & -0.598 & .508 \\
\hline Gender * Performance & & & & & & 0.281 & .306 & 1.324 & -0.508 & .070 \\
\hline Gender * Perc. Comp. & & & & & & -0.738 & .288 & $0.478^{*}$ & -1.481 & .005 \\
\hline Gender * Perc. Useful. & & & & & & 0.385 & .229 & 1.469 & -0.205 & .975 \\
\hline Gender* Interest & & & & & & -0.253 & .210 & 0.777 & -0.794 & .288 \\
\hline $\begin{array}{l}\text { Gender * Support from } \\
\text { parents }\end{array}$ & & & & & & 0.245 & .243 & 1.278 & -0.382 & .872 \\
\hline $\begin{array}{l}\text { Gender } * \text { Support from } \\
\text { friends }\end{array}$ & & & & & & -0.438 & .252 & 0.645 & -1.088 & .211 \\
\hline $\begin{array}{l}\text { Gender } * \text { Support from } \\
\text { teacher }\end{array}$ & & & & & & 0.238 & .215 & .269 & 0.316 & .792 \\
\hline
\end{tabular}

Note. Private/public status comparison category = private; Parents' education $1=$ elementary, high school, or other; Parents' education 2 = college; Comparison category = university; Gender comparison category = boy.

${ }^{*} \mathrm{p}<0.05$. ** $\mathrm{p}<0.01$. *** $\mathrm{p}<0.001$.

More specifically, the results showed that the higher the previous math performance, the greater the odds of being placed in an S over a TS sequence. Previous performance was less determinant for placement in Model 2 compared to Model 1. One unit increase in performance in second year high school increased the chances of being placed in an $\mathrm{S}$ over a TS sequence by 1.59 times. In addition, the chances of being placed in an $\mathrm{S}$ sequence were higher when the student took a specialized program. Attendance in a specialized program appeared to be determinant for placement, as it increased the chances of placement in an S over a TS sequence 1.58 times. School size was also significant in the model. The larger the school, the greater the chances of being placed in an $\mathrm{S}$ over a TS sequence. For boys, greater perceptions of competence increased their chances of being placed in an $\mathrm{S}$ over a TS sequence (odds ratio $=1.78$ ). Inversely, girls with greater perceptions of competence (perceived competence) were less likely to be placed in an $\mathrm{S}$ over a TS sequence (odds ratio $=0.48$ ). These were the most 
determinant effects, with perceived competence being more determinant for girls than for boys for math course placement.

\section{Discussion}

The main goal of this study was to explore individual, social, and school-based factors that are associated with placement in fourth year high school math in the context of the Quebec education reform. A significant percentage of the variance in math placement (pseudo R2 0.31-0.37) was explained by the different models tested. These results support the hypothesis that math placement cannot be explained by individual factors alone, and that social and school-based factors, such as previous tracking and parents' education and support (Jones, et al., 1995; Oakes, 1987; Oakes, et al., 1992), may also be influential.

\subsection{Placement in an Advanced over a Basic Sequence}

The first study objective was to determine what distinguishes students who were placed in an advanced over a basic math sequence in fourth year high school. As expected, previous performance was found to be an important individual determinant for placement: the better the student's previous performance, the greater the probability of being placed in an advanced sequence. As Rosenbaum (1978) concluded, even if the choice was left to the students, which was the case in the Québec education reform, they ended up being placed as if the school had assigned the sequences according to meritocratic criteria. Furthermore, researchers have found that students are often guided to choose sequences in light of their previous performance (Resh \& Erhard, 2002). This suggests that the students themselves referred to their previous math performance when choosing their sequence, and that the school might have done the same when actually placing students in the sequences.

Enrollment in a specialized program (enriched or sport-study), which constitutes an initial tracking system, was also determinant for course placement in an advanced math sequence. This result concurs with the theoretical model developed by Oakes (1987), whereby the school's organization can exert a strong influence on student placement, and previous placement strongly determines subsequent placement. Many schools that offer specialized programs cannot divide up their students into different-level math courses due to organizational constraints (e.g., minimum number of students per group, scheduling problems). Because these programs are usually elitist, and therefore accessible mainly to students who do well at school, they often include an advanced math sequence by default. In Quebec's education system, this organizational variable is influential, given that the public school system has offered increasing numbers of specialized programs across the five years of high school (Conseil supérieur de l'éducation, 2007).

Accordingly, our results showed that students who had attended a private school were more likely to be placed in an advanced over a basic math sequence. This can be explained in part by the selection effect, whereby private schools select their students based mainly on previous performance. Moreover, private schools might tend to offer more places in advanced than basic sequences. Organizational constraints could therefore account for placement in an advanced sequence independently of students' marks. Other factors, such as social factors, could also contribute to explain our results on private schools. It appears that students' surroundings differ according to whether they attend a private or public school. Previous studies have shown that teachers, parents, and peers have higher expectations for students who attended private schools (Lefebvre, Merrigan \& Verstraete, 2011; Alexander \& Cook, 1982), which could explain why private school students generally get higher marks in math, and consequently tend to be placed in advanced math courses.

Beyond the influence of individual and school-related factors, social factors also wield a non-negligible influence on math placement. In fact, having at least one well educated parent increased the likelihood of being placed in the advanced TS or S over the basic CST sequence. Other studies have demonstrated the importance of including this variable as a predictor of course placement (Alexander \& Cook, 1982; Kelly, 2004; Schiller et al., 2010). Having at least one well educated parent might be related to different influences on math placement: parents who place more importance on advanced math and therefore provide more support to their children to undertake an ambitious academic path (Kelly, 2004); parents who are strongly involved in the sequence selection process (Schiller et al., 2010; Useem, 1992); parents who are better than average at math, give their children more help with their math assignments, and consequently help build their child's confidence to undertake an advanced sequence (Yonezawa, 2000).

Finally, our results showed that, above and beyond previous math performance, students' perceptions of support from their parents and friends in choosing a math sequence were predictive of placement in advanced math sequences (TS or S). This finding suggests that math placement might also be influenced by significant figures in 
the students' environment, a factor that has been overlooked in previous theoretical propositions (Oakes, 1987). It is possible that parents who give their children more support are also more educated and more inclined to value their child's education. It is also plausible that support from parents fosters children's aspirations, which gives them more confidence in choosing an advanced math sequence. On the other hand, we know that students generally socialize with friends who are at the equivalent academic level, with similar social priorities and interests (Alexander \& Cook, 1982). When it comes to choosing an advanced math sequence, students might feel the need to be with friends who could help them do the work. This suggests that students who feel supported by their friends would feel more capable of passing an advanced math course.

Perceived competence, perceived usefulness, and general interest in math were not significant in determining placement in an advanced over a basic math sequence. There are a number of possible explanations for this. First, the main placement criterion used before the education reform was implemented was previous performance. It is therefore possible that students and their parents used this earlier criterion instead of considering motivation and interest toward math to make the choice. Moreover, Crombie and colleagues (2005) concluded that perceived competence and usefulness with respect to math predict more the intentions to enroll in advanced math courses than the actual choice and placement. Our results partly support this hypothesis. It is also possible that perceived competence was not significant due to its strong correlation with previous performance. In any case, despite the intentions behind the new programs, the fact remains that the TS and S options are more advanced than the CST Option, such that motivational factors would have less weight in the placement decision for students, parents, and schools alike.

Finally, we found no effect of gender or school's socioeconomic index (SSSI) on placement in an advanced over a basic sequence. First, it is possible that academic differences between boys and girls begin to dissipate once they reach high school. In addition, our descriptive data showed similar proportions of girls and boys in the sequences. Nevertheless, one might still assume that boys and girls would select courses for different reasons. Our results showed that, overall, this was not the case in our sample when it came to choosing an advanced over a basic sequence. On the other hand, it is possible that the school's socioeconomic status, measured in our study using the SSSI, was not related to placement, because all Quebec schools tend to offer the same sequences and use similar access procedures. Therefore, a school's low socioeconomic status would not be determinant for access to different sequences, unlike in the United States, for example. However, given the limited choice of indicators, among others, it would be premature to conclude that there was no effect of school's socioeconomic status on math course placement. Further studies are needed to clarify these relationships.

\subsection{Placement in One of the Two Advanced Sequences}

Next, we wanted to determine what distinguishes students who chose one over the other of the two advanced sequences offered under Quebec's education reform. Our results indicate that previous performance, enrollment in a specialized program, school size, and the interaction between gender and perceived competence were significantly associated with placement in one over the other of the sequences. More specifically, although both the TS and S options were designed as advanced sequences, previous math performance emerged as an important determinant for placement: stronger students were more likely to be placed in the S over the TS sequence. We propose that this could be explained in part by the different appeal of the two sequences and the way in which the school values them. Thus, the sequence called the Science (S) Option was designed to "develop strategies and acquire an academic background that specifically enables them [students] to pursue their studies in the hard sciences or to perhaps eventually specialize in research" (MELS, 2011). In other words, it prepares students for a career in the fields of mathematics, science, and technology (MST). In contrast, the Technical and Scientific (TS) Option does not necessarily lead to higher education studies: "This option encourages the exploration of different areas of study, but it is especially designed to equip students to work effectively in technical fields related to nutrition, biology, physics, business administration, the fine arts and graphic arts" (MELS, 2011). The TS Option is generally less valued socially, and consequently, the Government of Quebec has developed a variety of promotional campaigns for these professional and technical training programs. However, the social perceptions of these two sequences and the different values placed on them, which may have been shared by school staff and parents, are at odds with what is presented in the official program. Perhaps this is due to the newness of these recently implemented programs, or to lingering perceptions about previous sequences. In any case, the results showed that stronger students tended to pick the $\mathrm{S}$ Option, which is associated with a more prestigious academic and professional path. 
We then showed that, with performance held equal, the interaction between gender and perceived competence was significantly related to placement. This relationship appears to be stronger than that for previous performance. For boys, greater perceived competence increased their probability of being placed in the S over the TS sequence. Inversely, for girls, the greater their perceived competence, the more likely they were to be placed in the TS over the S sequence. This puzzling result could be explained by a number of hypotheses that merit further exploration. It is possible that boys who feel more competent in math would be attracted to the sequence that appeared more prestigious, that is, the S Option. It has been argued that boys place higher value on job status and have higher self-perception than girls, which would explain the different choice between the two sexes (see Eccles, 2011). Another explanation is that the TS Option is associated with career paths that girls have not traditionally taken (e.g., mechanical engineering, electronics). Therefore, only girls with strong perceived competence in math would be attracted to the TS Option.

Finally, enrollment in a specialized program and school size were associated with student placement. As expected, it was found that larger schools are able to offer all the sequences under the MELS program. However, when a school is smaller, it must reduce the offer to just two sequences. According to the results, such schools usually decide on the $\mathrm{S}$ over the TS sequence. Moreover, enrollment in a specialized program appears to have led primarily to placement in the S Option. These results could also be explained by the above-presented hypothesis, whereby the S Option would be valued more highly than the TS Option.

\section{Conclusions and Implications}

Our results lead to some important conclusions for education actors and decision makers. First, the new math programs were designed to eliminate discrimination between students who were strong and weak in math, and to offer different types of math courses for different end uses. In this way, students could choose a math option based on their interests and information needs, and not be classified simply on the basis of previous performance. Our results suggest that previous performance remains an important determinant of course placement, but that beyond performance, other factors make a substantial and significant contribution.

In addition, although the programs were designed to offer two advanced options considered equally difficult (TS and S), it appears that students view them differently according to gender and perceived competence. The courses offered in these two options should therefore be examined more closely to better understand why boys and girls with high perceived competence would be differentially distributed in the two sequences.

According to the education programs, students should have access to the math sequence that best corresponds to their aptitudes, needs, and interests. However, we note that almost all the students who attended specialized programs ended up in the S sequence. In light of this finding, we might wonder if these students really had a choice in the matter.

Furthermore, the results suggest the importance of familiarizing students with the math options so that the poverty cycle is not repeated: when performance was held equal, students from less well educated families usually ended up taking the CST Option. Different actors could contribute to this approach. First, even when parents have little input in the choice of sequence, the effect on some students is not negligible. Encouraging students to explore and discover their interests in various math-related fields should not be the responsibility of the school staff alone; it should be a family concern as well. It would therefore be important for schools to ensure that parents are well informed about the three options offered to their children, and to provide some guidance for their role in helping their children select an option. On the other hand, our results showed that perceived support from school staff in choosing a sequence does not have a significant effect on placement. Schools could therefore raise awareness of this guidance role - particularly by third year high school math teachers - in helping students make their choice. Special attention should be paid to the differences between the two advanced math sequences in order to clarify what distinguishes them, while avoiding stereotyped messages.

That said, the results of this study have certain limitations. First, because the sample considered for this study differs slightly but significantly from the initial probabilistic sample, the findings should be generalized with caution. Thus, the students retained appear to be more academically advantaged on average than if there was no attrition. Next, perceptions of support from parents, friends, teachers, and guidance counselors were measured with a single item at Time 2, when the students were already in fourth year high school. It is possible that if the students had been surveyed at the end of the third year, when they were choosing their option, this variable might have explained more of the variance. In addition, it is possible that the variable general interest in math and sciences was too general. A variable measuring the degree of interest in math courses might have been more strongly related to math course placement. 
Furthermore, we knew little about the actual tracking criteria used by the schools, or the actual sequence offer, which limits the results interpretation. Finally, a more thorough knowledge of the school environment (e.g., repeat rates, percentage of students with handicaps or learning problems) would have enabled us to better determine whether the relationships between the variables and course placement were due to individual school characteristics.

Other factors can be taken into account to explain placement and sequence choice. For instance, other individual factors (e.g., ethnicity, value placed on math, and performance anxiety), organizational factors (e.g., school size and climate), and social factors (e.g., available resources at home, parent-child discussions about school, parental expectations, and relationship with math teacher) can contribute to predict placement (Lewis \& Cheng, 2006; Ma, 2001; Newton, 2010). Although it was impossible to measure the influence of all these factors in this study, it would be important to pursue our investigations to determine the relative weight of these factors in today's education system. Other analyses could explore the indirect associations between the model variables. Finally, because students' input counted towards placement in the present study, it would be useful to determine differences between placement determinants according to whether or not students could access their chosen option.

\section{References}

Alexander, K. L., \& Cook, M. A. (1982). Curricula and coursework: A surprise ending to a familiar story. American Sociological Review, 47(5), 626-640. http://dx.doi.org/10.2307/2095163

Conseil canadien sur l'apprentissage-Carnet du savoir. (2006). L'écart éducatif entre les zones rurales et $\begin{array}{lllll}\text { urbaines. } & \text { Retrieved } & \text { August } & \text { 2012, }\end{array}$ http://www.ccl-cca.ca/CCL/Reports/LessonsInLearning/index-2.html

Conseil supérieur de l'éducation. (2007). Les projets pédagogiques particuliers au secondaire: diversifier en toute équité. Avis au ministre de l'éducation, du loisir et du sport, Québec.

Crombie, G., Sinclair, N., Silverthorn, N., Byrne, B., DuBois, D., \& Trinneer, A. (2005). Predictors of young adolescents' math grades and course enrollment intentions: Gender similarities and differences. Sex Roles, 52(5), 351-367. http://dx.doi.org/10.1007/s11199-005-2678-1

Direction de la recherche en politiques et coordination. (2004). Perspectives du marché du travail canadien pour la prochaine décennie, 2004-2013. Gatineau, Québec: Ressources humaines et développement des compétences Canada: Gouvernement du Canada.

Eccles, J. (2011). Gendered educational and occupational choices: Applying the Eccles et al. model of achievement-related choices. International Journal of Behavioral Development, 35(3), 195-201. http://dx.doi.org/10.1177/0165025411398185

Engberg, M., \& Wolniak, G. (2010). Examining the effects of high school contexts on postsecondary enrollment. Research in higher education, 51(2), 132-153. http://dx.doi.org/10.1007/s11162-009-9150-y

Falter, J.-M., Luzzi, G. F., \& Sbergami, F. (2010). The effect of parental background on track choices and wages. Switzerland: University of Geneva.

Fennema, E., \& Sherman, J. A. (1976). Fennema-Sherman mathematics attitudes scales: Instruments designed to measure attitudes toward the learning of mathematics by females and males. Journal for Research in Mathematics Education, 7(5), 324-326. http://dx.doi.org/10.2307/748467

Hallinan, M. T. (1992). The organization of students for instruction in the middle school. Sociology of Education, 65(2), 114-127. http://dx.doi.org/10.2307/2112678

Hattie, J. A. C. (2009). Visible learning: A synthesis of over 800 meta-analyses relating to achievement. London and New-York: Routledge.

Ingersoll, R. M., \& Perda, D. (2010). Is the supply of mathematics and science teachers sufficient? American Educational Research Journal, 47(3), 563-594. http://dx.doi.org/10.3102/0002831210370711

Ireson, J., \& Hallam, S. (2009). Academic self-concepts in adolescence: Relations with achievement and ability grouping in schools. Learning and Instruction, 19(3), 201-213. http://dx.doi.org/10.1016/j.learninstruc.2008.04.001

Jones, J. D., Vanfossen, B. E., \& Ensminger, M. E. (1995). Individual and organizational predictors of high school track placement. Sociology of Education, 68(4), 287-300. http://dx.doi.org/10.2307/2112743 
Kelly, S. (2004). Do increased levels of parental involvement account for social class differences in track placement? Social Science Research, 33(4), 626-659. http://dx.doi.org/10.1016/j.ssresearch.2003.11.002

Lefebvre, P., Merrigan, P., \& Verstraete, M. (2011). Public subsidies to private schools do make a difference for achievement in mathematics: Longitudinal evidence from Canada. Economics of Education Review, 30, 79-98. http://dx.doi.org/10.1016/j.econedurev.2010.07.005

Lessard, V. (2007). La valeur prédictive de la motivation en mathématiques des élèves de 3e secondaire sur le classement en 4e secondaire. Mémoire de maîtrise inédit, Université de Montréal, Québec, Canada.

Lessard, V., Chouinard, R., \& Bergeron, J. (2009). Valeur prédictive de la motivation sur le classement en mathématiques. Revue des sciences de l'éducation, 25(3), 217-235. http://dx.doi.org/10.7202/039863ar

Lewis, T., \& Cheng, S. (2006). Tracking, expectations, and the transformation of vocational education. American Journal of Education, 113(1), 67-99. http://dx.doi.org/10.1086/506494

Losier, G. F., Vallerand, R. J., \& Blais, M. R. (1993). Construction et validation de l'échelle des perceptions de compétence dans les domaines de vie (EPCDV). Sciences et Comportement, 23, 1-16.

Ma, X. (2001). Participation in advanced mathematics: Do expectation and influence of students, peers, teachers, and parents matter? Contemporary Educational Psychology, 26(1), 132-146. http://dx.doi.org/10.1006/ceps.2000.1050

Ma, X., \& Johnson, W. (2008). Mathematics as the critical filter: Curricular effects on gendered career choices. In H. G. Watt, \& J. S. Eccles (Eds.), Gender and occupational outcomes: Longitudinal assessments of individual, social and cultural influences (pp. 55-83). Washington, D.C.: APA Books.

Ministère de l'éducation, du loisir et du sport. (2005). Direction de la sanction des études. Données non publiées.

Ministère de l'éducation du loisir et du sport. (2006). Programme de formation de l'école québécoise. Enseignement secondaire. Québec: Gouvernement du Québec.

Ministère de l'éducation du loisir et du sport. (2007). Programme de formation de l'école québécoise: Enseignement secondaire, deuxième cycle. Domaine de la mathématique, de la science et de la technologie. Québec: Gouvernement du Québec.

Ministère de l'éducation du loisir et du sport. (2008). Indices de défavorisation 2008-2009. Dans Section Publications et statistiques (Ed.). Québec: Gouvernement du Québec.

Newton, X. (2010). End-of-high-school mathematics attainment: How did students get there? Teachers College Record, 112(4), 5.

Oakes, J. (1987). Tracking in secondary schools: A contextual perspective. Educational Psychologist, 22(2), 129-153. http://dx.doi.org/10.1207/s15326985ep2202_3

Oakes, J., Gamoran, A., \& Page, R. (1992). Curriculum differentiation: Opportunities, outcomes and meanings. In P. Jackson (Ed.), Handbook of research on curriculum (pp. 570-608). New-York: Macmillan.

Oakes, J., \& Guiton, G. (1995). Matchmaking: The dynamics of high school tracking decisions. American Educational Research Journal, 32(1), 3-33. http://dx.doi.org/10.3102/00028312032001003

Pajares, F., \& Graham, L. (1999). Self-efficacy, motivation constructs, and mathematics performance of entering middle school students. Contemporary Educational Psychology, 24(2), 124-139. http://dx.doi.org/10.1006/ceps.1998.0991

Pajares, F., \& Miller, M. (1995). Mathematics self-efficacy and mathematics performances: The need for specificity of assessment. Journal of Counseling Psychology, 42(2), 190-198. http://dx.doi.org/10.1037/0022-0167.42.2.190

Resh, N. (1998). Track placement: How the "sorting machine" works in Israel. American Journal of Education, 106(3), 416-438. http://dx.doi.org/10.1086/444190

Resh, N., \& Erhard, R. (2002). "Pushing-up" or "Cooling-out”? Israeli counselors' guidance on track placement. Interchange, 33(4), 325-349. http://dx.doi.org/10.1023/A:1021537720071

Rosenbaum, J. E. (1978). The structure of opportunity in school. Social Forces, 57, 236. http://dx.doi.org/10.2307/2577636 
Russo, G. (2009). Emerging shortages. Nature, 462, 375. http://dx.doi.org/10.1038/nj7271-375a

Schiller, L. S., Schmidt, W. H., Muller, C., \& Houang, R. T. (2010). Hidden disparities: How courses and curricula shape opportunities in mathematics during high school. Equity and Excellence in Education, 43(4), 414-433. http://dx.doi.org/10.1080/10665684.2010.517062

Smith, E., \& Gorard, S. (2011). Is there a shortage of scientists? A re-analysis of supply for the UK. British Journal of Educational Studies, 59(2), 159-177. http://dx.doi.org/10.1080/00071005.2011.578567

Spade, J. Z., Columba, L., \& Vanfossen, B. E. (1997). Tracking in mathematics and science: Courses and course-selection procedures. Sociology of Education, 70(2), 108-127. http://dx.doi.org/10.2307/2673159

Useem, E. L. (1992). Middle schools and math groups: Parents' involvement in children's placement. Sociology of Education, 65(4), 263-279. http://dx.doi.org/10.2307/2112770

Vezeau, C., Chouinard, R., Bouffard, T., \& Couture, N. (1998). Adaptation et validation des échelles de Fennema-Sherman sur les attitudes en mathématiques chez des garçons et des filles du secondaire. Revue canadienne des sciences du comportement, 30, 137-140. http://dx.doi.org/10.1037/h0085804

Watt, H. M. G. (2008). What motivates females and males to pursue sex-stereotyped careers? In H. M. G. Watt, \& J. S. Eccles (Eds.), Gender and occupational outcomes: Longitudinal assessments of individual, social and cultural influences. Washington, D.C.: APA Books.

Yonezawa, S. S. (2000). Unpacking the black box of tracking decisions: Critical tales of families navigating the course placement process. In M. G. Sanders (Ed.), Schooling students placed at risk: research, policy, and practice in the education of poor and minority adolescents (pp. 109-140). Mahwah, NJ: Lawrence Erlbaum Associates.

\section{Copyrights}

Copyright for this article is retained by the author, with first publication rights granted to the journal.

This is an open-access article distributed under the terms and conditions of the Creative Commons Attribution license (http://creativecommons.org/licenses/by/3.0/). 